\title{
Assessment of various deleterious oral habits and its effects on primary dentition among 3-5 years old children in Davangere city
}

\author{
Rashmi G. Chour*, Suryakanth M. Pai' ${ }^{2}$, Girish V. Chour³, Sangeetha M. Kenchappannavar², \\ Poornima Parameshwarappa ${ }^{2}$ \\ Departments of ${ }^{1}$ Pedodontics and ${ }^{3}$ Oral and Maxillofacial Surgery, PMNM Dental College and Hospital, Bagalkot, \\ ${ }^{2}$ Department of Pedodontics, College of Dental Sciences, Davangere, Karnataka, India
}

\begin{abstract}
Childhood is the mirror which reflects the propensities of adulthood. The objective of this crosssectional study was to determine the prevalence of malocclusion, deleterious oral habits and relationship of deleterious oral habits and malocclusions in 3-5 years old children. A cross-sectional study was conducted among 800 school children aged ranges between 3 and 5 years who were randomly selected from 10 different public schools in Davangere city, India. Occlusal assessments and clinical examination for assessing the oral habits was carried out. After obtaining the data, Chi-square test and $Z$-test were used to analyze the data. The results showed the prevalence of malocclusion was $8.9 \%$ and of various deleterious oral habits was $47.2 \%$. Tongue thrusting $(29.5 \%)$ was most commonly observed habit followed by mouth-breathing (26.5\%). In the presence of deleterious, oral habits $13 \%$ of children were observed with the malocclusions. The prevalence of normal deciduous dentition was observed in $87 \%$ of children even in the presence of habits. Prevalence of oral habits observed was highly significant constituting $47.2 \%$ and the correlation between prevalence of oral habits and malocclusions in deciduous dentition does not seem to be strong, but we found tongue thrusting and mouth-breathing habit more in this age group constituting $29.5 \%$ and $26.2 \%$, respectively, contributing to the malocclusion.
\end{abstract}

Key words: Deleterious oral habits, Malocclusion, Primary dentition

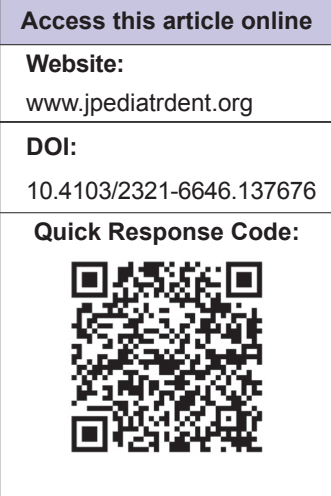

\section{INTRODUCTION}

O ral function is comprised of articulation, swallowing and chewing. Malocclusion may be caused by abnormal functions such as mouth-breathing, tongue thrusting, swallowing and unilateral chewing and by abnormal postures of oro-circumferential muscles such as forward tongue thrust, tongue biting, and low tongue at rest. Forces from unilateral and habitual behaviors constantly acting on the maxillofacial and alveolar regions can cause the bony structures to generally deform, resulting in jaw deformity and malocclusion. ${ }^{[1]}$ Malocclusion is frequent in the populations, irrespective of geographical area, ethnic group, gender, age, or social class and has been of a morphological variation and not pathological conditions. ${ }^{[2]}$
When considering the etiology of malocclusion, most textbooks list the possible factors without providing a working hypothesis with which to balance their clinical relevance. Congenital defects and trauma are always listed, but are generally accepted as responsible for $<5 \%$ of malocclusions. The influence of muscle activity, posture, and various deleterious habits are usually included, but listed under local factors and little guidance is given about the extent of their impact or how they can be assessed. Without a clear understanding of the etiology of any condition, there is a risk that treatment becomes empirical or symptomatic. A synergistic influence of the combination of high caries rate in deciduous dentition and coexistence of deleterious oral habits is commonly seen. ${ }^{[3-10,21]}$

\footnotetext{
*Address for correspondence

Dr. Rashmi G. Chour, Department of Pedodontics, PMNM Dental College and Hospital, Bagalkot - 587 101, Karnataka, India.

E-mail: rashmi.dentist@gmail.com
} 
Although a number of studies correlating deleterious oral habits and their effects on mixed dentition have been documented with the incidence ranging from $33.37 \%$ to $55 \%,{ }^{[3-9]}$ the literature with regard to the effect of deleterious oral habits on deciduous dentition is sparse. Therefore, this study attempts to understand the relationship of deleterious oral habits and malocclusions in deciduous dentition.

\section{Objectives}

This study was carried out with the following aims and objectives:

- To determine the prevalence of malocclusion in deciduous dentition.

- To determine the prevalence of deleterious oral habits such as tongue thrusting, thumb sucking, and mouthbreathing in 3-5 years old children.

- To determine the correlation between the prevalence of malocclusion and the presence/absence of deleterious oral habits.

- To assess whether the normal deciduous dentition can exist even in the presence of deleterious oral habits.

\section{MATERIALS AND METHODS}

\section{Source of data}

A cross-sectional study was conducted to determine the prevalence of oral habits and its relationship with malocclusion. A list of 10 different public schools was randomly selected among 52 public schools in the Davangere city, Karnataka state, India, owing to the age consideration of the study population. A total of 1082 children (3-5 years old) with complete primary dentitions were examined by single examiner out of which 800 were randomly selected (485 girls and 315 boys) who satisfied the following inclusion criteria.

\section{Inclusion criteria}

- $\quad$ Study subjects aged between 3 and 5 years.

- All functional deciduous teeth should be present.

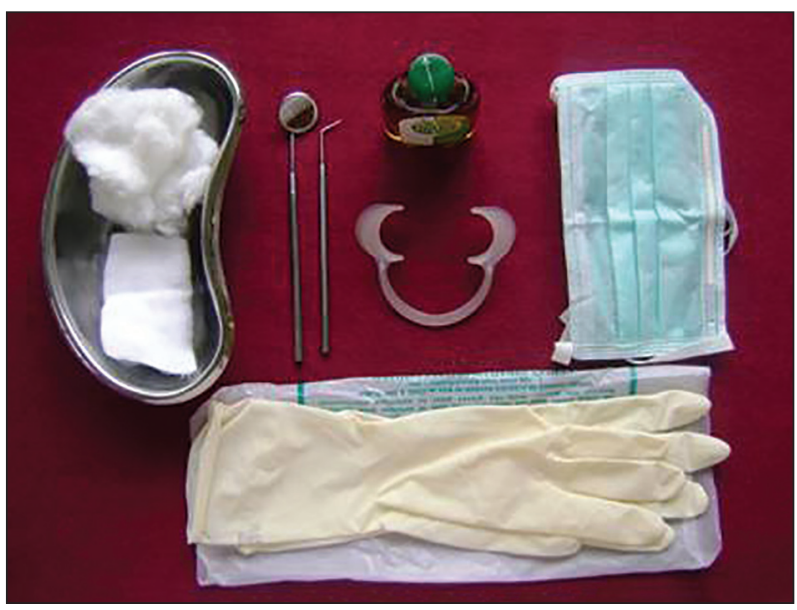

Figure 1: Armamentarium used for the study

\section{Exclusion criteria}

- Children with congenitally missing teeth.

- Children with deviated nasal septum, enlarged adenoids, clefts of the lip/palate.

- Children with systemic disorders such as respiratory disorders, neuromuscular, and cardiac disorders.

- Children under orthodontic intervention.

Prior to the clinical examination, parents were given a questionnaire form to fill about the medical history, thumb sucking, nail biting and lip sucking habits and were also informed about the procedure. Informed parental consent was obtained before commencing the study. The research protocol of the study was reviewed and approved by the Ethical Committee of the institution.

\section{Questionnaire}

Self-designed questionnaire was prepared to collect the information pertaining to study after obtaining the consent from parent/legal guardian. While data regarding the habits such as thumb sucking, nail biting and lip sucking, etc., were obtained from written questionnaire forms answered by the parents, the tongue thrusting and mouth-breathing habits were investigated by a single examiner.

\section{Armamentarium and materials used in the study}

Disposable gloves and mouth mask, sterile gauze pads and cotton, mouth mirror no. 5, straight explorer no. 6 [Figure I].

\section{Oral habits examination}

\section{Tongue thrusting}

The subjects were seated upright on the chair. The fingers of both the hands of the examiner were used to palpate the masseter muscle, while both the thumbs were used simultaneously to retract the lower lip lightly so that the tongue thrust if present could be seen [Figure 2]. With the hands in this position, the subjects

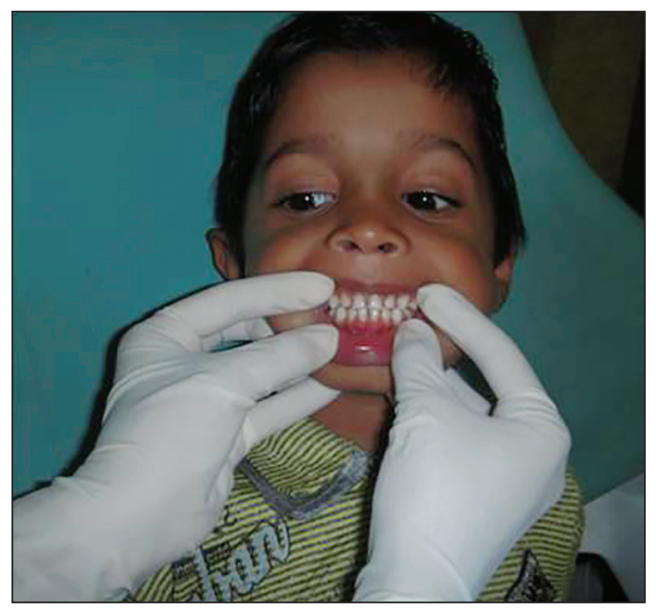

Figure 2: Examination position used to identify tongue-thrust swallowing 
were asked to swallow the saliva; subjects in whom there was diminution or absence of palpable contraction of masseter muscle as well as forward thrust of tongue causing it to protrude between the incisors were ranked as tongue thrust swallowers. Subjects who didn't demonstrate the above-mentioned habit were classified as normal swallowers. ${ }^{[1]}$

\section{Mouth-breathing}

Breathing pattern was determined by clinical evaluation and specific test (water holding test). Clinical evaluation determined the presence or absence of the following signs Long face, drooping eyes, thin upper lip, dry lips, hypotonic lips, inverted lower lip, narrow nostrils, high arched palate, inadequate lip seal, and anterior open bite. The water-in-mouth test involved the child holding water in his/her mouth with the lips closed and without swallowing for 3-min [Figure 3]. The lip commissure was observed for signs of effort; children who were unable to keep their lips closed over the 3-min period were considered mouth breathers. ${ }^{[12]}$

Data were registered by an assistant in dental records especially elaborated for this study.

\section{Clinical examination}

A survey proforma was created to gather data from the sample. The children were examined by a single examiner.

The clinical examination was accomplished by a single examiner under natural light, each child lay on the chair with the head aided by cushion and hence that the whole oral cavity was visualized. Gauze was used to dry the teeth before examining both upper and lower arch.

Each child was requested to open the mouth, to allow for the examination of teeth (number, form, and arrangement)

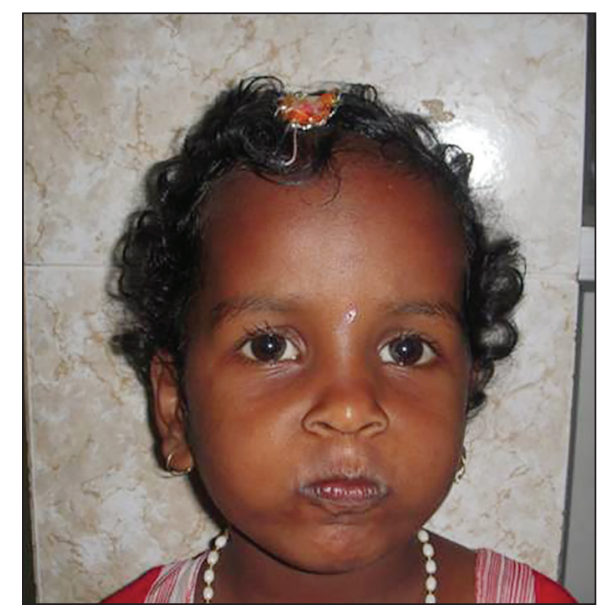

Figure 3: Examination of mouth breathing and integrity of dental arches and shape. The child was asked to bite in centric occlusion to check for the amount of overjet, overbite, and the type of occlusion.

It has been considered as normal occlusion when the buccal surfaces of the upper teeth were located outside the buccal surfaces of the lower teeth and the overjet and overbite were $0-3 \mathrm{~mm}$. The inverted buccal-lingual relationships as in the anterior region (anterior crossbite) or posterior region (posterior crossbite) areas, as well as the overbite over $3 \mathrm{~mm}$ (deep bite) or absent (open bite) were considered as malocclusions.

The presence of malocclusion was recorded according to the following traits: Distal molar relation, class II canine relation, posterior crossbite, anterior open bite, and overjet $>4 \mathrm{~mm}$.

\section{Statistical methods}

Chi-square analysis was used to analyze the effect of the various deleterious oral habits on the prevalence of malocclusion. The Z-test for proportion was used to compare the proportions of the signs of malocclusion among the different types of deleterious oral habits. $P<0.05$ was considered as significant.

\section{RESULTS}

A cross-sectional study was conducted to determine the prevalence of oral habits and its relationship with malocclusion. A total of 800 were distributed according to age and sex, majority being girls that is, $60.6 \%$ whereas boys constituted $39.4 \%$ [Table I].

A total of 7 I children with different types of malocclusion were found in the total sample size of 800 , suggesting a prevalence of $8.9 \%$. Of a total of 71 malocclusion cases that were identified in our study the most common malocclusion was anterior open bite [Figure 4] with a prevalence of $3.4 \%$ followed by increased overjet $2.6 \%$, posterior crossbite [Figure 5] $1.2 \%$, anterior crossbite [Figure 6] $1.6 \%$, lower anterior crowding $0.6 \%$, and anterior openbite along with unilateral posterior crossbite was $0.1 \%$ [Table 2 and Graph I].

Table 1: Represents age and gender wise distribution of the study population

\begin{tabular}{lcccc}
\hline Age (years) & $\begin{array}{c}\text { No. of } \\
\text { children }\end{array}$ & Percentage & \multicolumn{2}{c}{ Gender } \\
\cline { 3 - 5 } & & & Female (\%) & Male (\%) \\
\hline 3 & 47 & 5.9 & $116(14.5)$ & $80(10.0)$ \\
4 & 410 & 51.2 & $158(19.7)$ & $110(13.7)$ \\
5 & 343 & 42.9 & $211(26.3)$ & $125(15.6)$ \\
Total & 800 & 100 & $485(60.6)$ & $315(39.4)$ \\
\hline
\end{tabular}


A total of 378 children with either one or more deleterious oral habits in the total sample size of 800 , which suggests a prevalence of $47.2 \%$ tongue thrusting was the most commonly observed habit with a prevalence of $29.5 \%$ followed by mouth-breathing with $26.2 \%$ and thumb sucking, which was statistically insignificant with prevalence of $0.2 \%$ [Table 3 and Graph 2].

Of 378 children, 7I had multiple oral habits, only 49 (13\%) of them were associated with concurrent presence of one or more oral habits. The remaining 22 (5.2\%) had malocclusion with no associated oral habits. Of 378 children observed with one or more oral habits, 329 $(87 \%)$ children were observed with normal occlusion [Figure 7, Table 4 and Graph 3].

\section{DISCUSSION}

Dental literature on malocclusions in mixed and permanent dentition and their correlation to various deleterious oral habits has been well-documented. According to Frazão et al., the prevalence of malocclusions

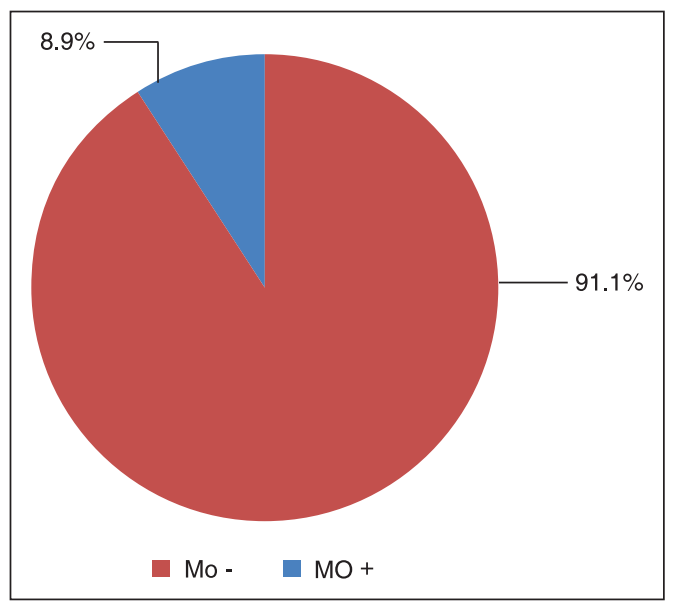

Graph 1: Prevalence of malocclusion among 3-5 years children

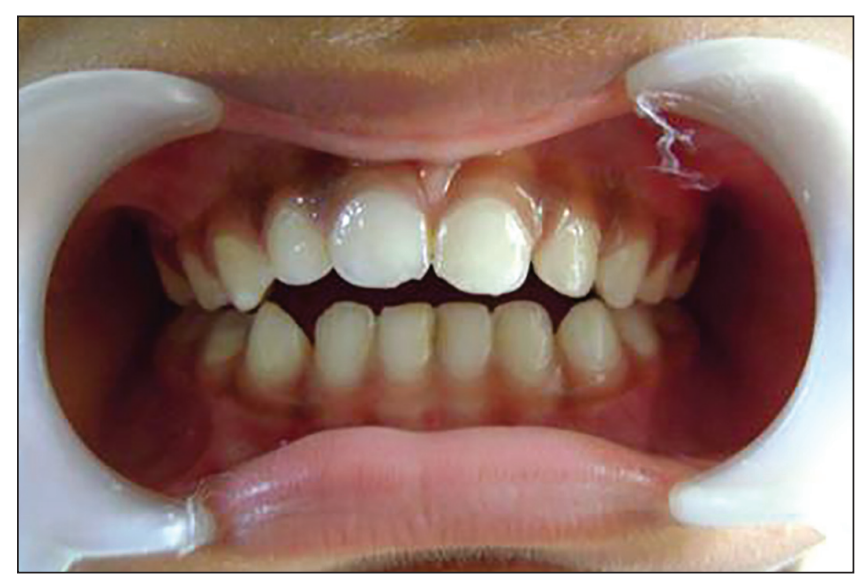

Figure 5: Anterior open bite due to digit sucking increased from $49.0 \%$ in the deciduous dentition to $71.3 \%$ in the permanent dentition. ${ }^{[13]}$ However, very few studies have been conducted with regard to prevalence of

Table 2: Represents types of observed malocclusion

\begin{tabular}{lcc}
\hline Type of malocclusion & $\begin{array}{c}\text { Children with } \\
\text { malocclusion }\end{array}$ & Percentage \\
\hline Anterior open bite & 27 & 3.4 \\
Increased overjet & 21 & 2.6 \\
Anterior crossbite & 13 & 1.6 \\
Posterior crossbite & 10 & 1.2 \\
Lower anterior crowding & 5 & 0.6 \\
Anterior open bite, unilateral & 1 & 0.1 \\
posterior crossbite & & \\
Total & 71 & 8.9 \\
\hline
\end{tabular}

Table 3: Represents the distribution of deleterious habits among the study population

\begin{tabular}{lcc}
\hline Habits & No. of children & Percentage \\
\hline Tongue thrusting & 236 & 29.5 \\
Mouth breathing & 210 & 26.2 \\
Thumb sucking & 2 & 0.2 \\
Total & 378 & 47.2 \\
\hline 378 children have multiple habits &
\end{tabular}

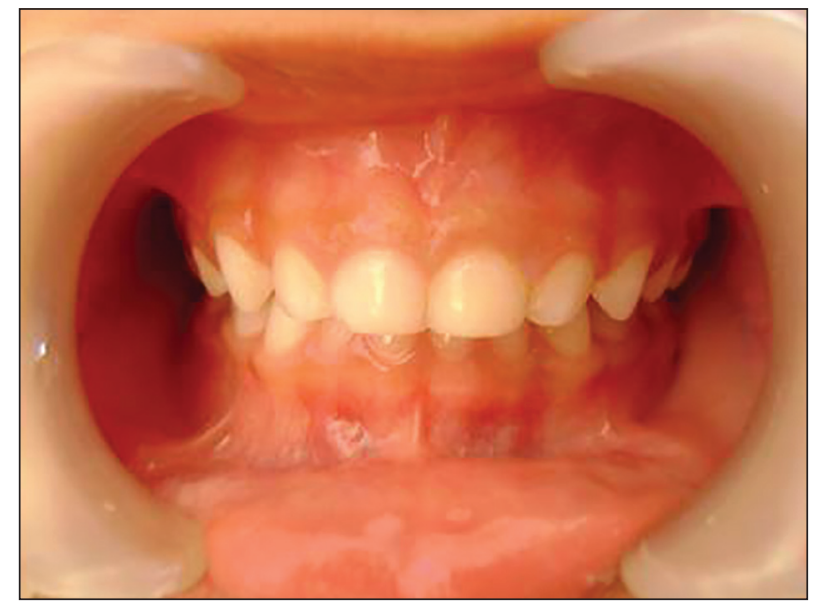

Figure 4: Healthy primary dentition

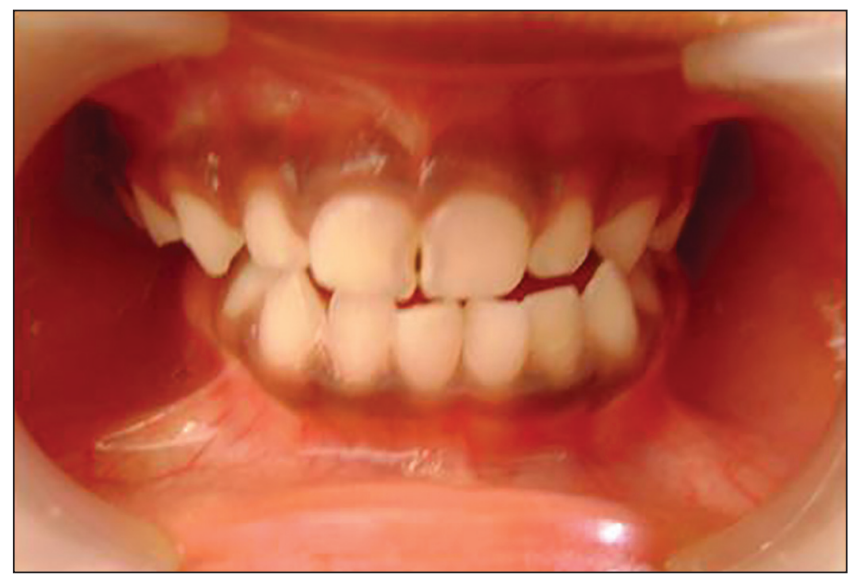

Figure 6: Posterior buccal crossbite 
malocclusions in deciduous teeth and their correlation to various deleterious oral habits though habits do have role in causing malocclusion in primary dentition; ${ }^{[2,13,14]}$ hence, the age group of 3-5 years was selected.

The present research therefore is an attempt to study the correlation between malocclusions in deciduous dentition and the influence of various oral habits on the deciduous dentition.

We have carried out this study on a randomly selected sample size of 800 children represented by ten different public schools with all children falling in the age group of 3-5 years. This age range has helped us eliminate those children with an incompletely developed occlusion or those with mixed dentition.

The first objective of our study was to know the prevalence of malocclusion in deciduous dentition. Our finding of $8.9 \%$ prevalence is in sharp contrast to the finding of Chevitarese et al., who have reported prevalence as high as $75.8 \%$ in the primary dentition. The total sample size in their study was 112 compared with the 800 sample size in our present study. This would probably explain the sharp divergence in the findings. ${ }^{[2]}$ Vázquez-Nava et al., found a $58.5 \%$ prevalence of malocclusion in a total sample size of 690 children, ${ }^{[15]}$ in this study the coexistence of allergic rhinitis and oral habits was analyzed and this could explain the divergence in their findings as compared with the findings of our present study.

These findings of our study are in agreement with studies conducted by Fukuta et al. who retrospectively reviewed dental records of 930 Japanese children aged 3-5 years, and found "maxillary protrusion" and anterior open bite more common among children with habits. ${ }^{[14]}$

The second objective of our study was to know the prevalence of oral habits in deciduous dentition. Nanda et al., ${ }^{[16]}$ studied the effects of oral habits on the occlusion in preschool children and found $17 \%$ of children had oral habits, maximum number seen in age group of 3-4 years. Thumb sucking was found to be the most common with highest prevalence. Mouth-breathing constituted nearly $27 \%$ and tongue thrusting about 19\%. Our present study

Table 4: Represents the correlation between malocclusion and oral habits in the study population

\begin{tabular}{lccc}
\hline Habits & \multicolumn{2}{c}{ Malocclusion } & \multirow{2}{*}{$\begin{array}{c}\text { Total } \\
\end{array}$} \\
\cline { 2 - 3 } & Present & Absent & \\
\cline { 2 - 3 } & $n(\%)$ & $n(\%)$ & \\
\hline Present & $49(13.0)$ & $329(87.0)$ & $378(100)$ \\
Absent & $22(5.2)$ & $400(94.8)$ & $422(100)$ \\
Total & $71(8.9)$ & $729(91.1)$ & $800(100)$ \\
\hline
\end{tabular}

Chi-square: $14.81 \mathrm{df}=1, P<0.001$, Highly significant is in disagreement with Nanda et al. ${ }^{[16]}$ as we observed the prevalence of oral habits up to $47.2 \%$ and tongue thrusting habit was most commonly seen with prevalence of $29.5 \%$.

In our present study, we observed tongue thrusting as the most common oral habit constituting $29.5 \%$. It can be explained on the basis that tongue tip function during swallowing is directly-related to the differences in the contiguous anterior dentoskeletal environment. The varying patterns of tongue tip movement seem to represent a functional adaptation to the differences in the

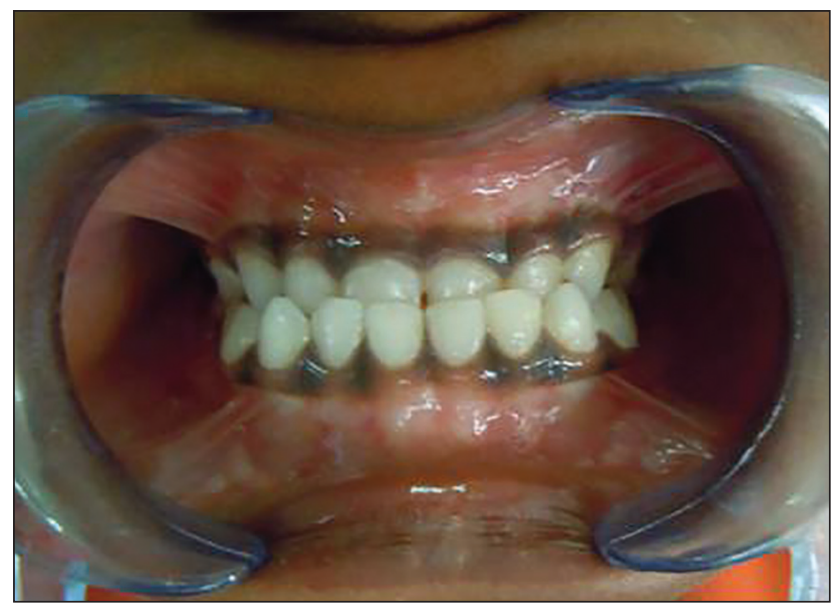

Figure 7: Anterior crossbite

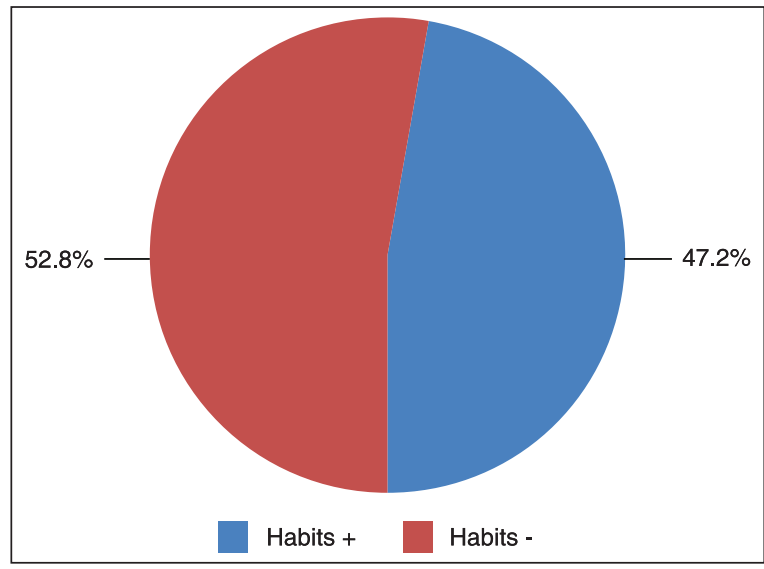

Graph 2: Prevalence of oral habits among 3-5 years children

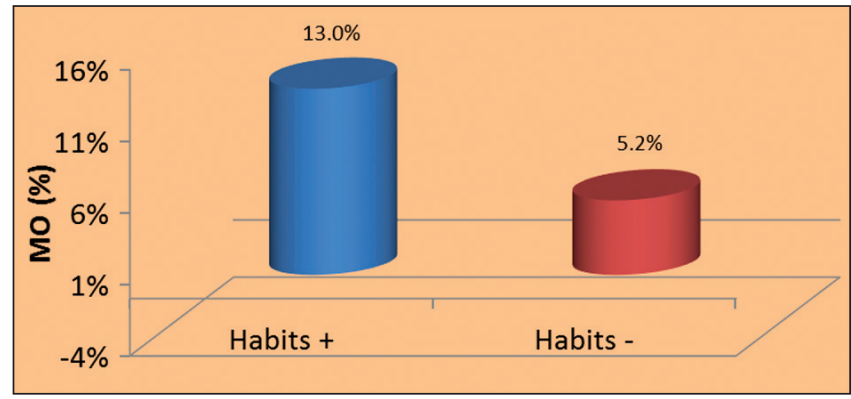

Graph 3: Prevalence of malocclusion associated with the oral habits 
configuration of the anterior malocclusion. Perhaps this functional adaptation represents an attempt to achieve an anterior oral seal during swallowing and compensation to the aberration in the anterior oral environment. Thus, an adaptation to an existent environment may yet be another explanation for the apparent prevalence of tongue thrusting in young age groups. Many authors have observed that the intermolar distance was statistically smaller in mouth-breathing patients when compared with that of nasal breathers, which indicates a larger narrowing of maxillary arch in the second molar area. ${ }^{[17]}$

Cheng et al. ${ }^{[18]}$ and Bresolin et al. ${ }^{[19]}$ evaluated children from different age groups and reported a greater prevalence of posterior crossbite in mouth-breathing children. These findings were corroborated by Melson et al. who reported that posterior crossbite and anterior openbite were most commonly observed malocclusion in mouth breathers; we have found a relatively high $26.2 \%$ prevalence of mouth-breathing.

In this study, we have observed the prevalence of mouthbreathing as $26.2 \%$ which is statistically significant. It is not unusual for a child to continue mouth-breathing even after the nasal airway has been made patent. Some children who have never had any significant nasal airway obstruction develop an open-mouth posture and or mouth-breathing habit to imitate family or friends, because of a short upper lip, or merely as an acquired habit.

In this study, the prevalence of oral habits observed was $47.2 \%$ which is statistically significant as compared with the studies mentioned above. This could probably be because of the racial difference and method used for examination of oral habits.

The third objective of our study was to determine the correlation between the prevalence of malocclusion and presence/absence of deleterious oral habits. Our study is in agreement with one other study conducted to know the influence of chronic mouth-breathing on dentofacial growth and development in preschool children of 3-6 years of age of both the sexes. After otorhinolaryngological breathing diagnosis, mouth-breathing and nasal-breathing children were compared according to facial and occlusal characteristics. The skeletal pattern measurements SN, GoGn, BaN.PtGn, PP.PM, Ar-Go, S-Go indicated a tendency of mouth-breathing children presenting a dolicofacial pattern, ${ }^{[17]}$ it can be concluded that mouth-breathing can influence craniofacial and occlusal development early in childhood. ${ }^{[17]}$

The fourth objective of our study was to assess whether the normal deciduous dentition can exist even in the presence of deleterious oral habits. In this study, the prevalence of malocclusion in primary dentition is statistically insignificant that is, $8.9 \%$ though the children presented with oral habits was statistically significant constituting $47.4 \%$. These findings are at variance with a number of similar studies conducted in mixed dentition. This shows that the prevalence of malocclusion increases from primary to mixed dentition. ${ }^{[4,5,7,8]}$

In our study, the prevalence of oral habits is significant in primary dentition, but the prevalence of malocclusion in primary dentition is not significant, which may be because of transitional swallow, this period lasting from the $2^{\text {nd }}$ to $8^{\text {th }}$ years of life, Profit and Mason, 1975. Earlier reports showed that the change from infantile to adult swallowing patterns occurred at about two and half to 3 years of age, Gwynne - Evans 1951, while a study conducted by Lewis and Counihan 1965, found the change to be around the age of 5 years. ${ }^{[20]}$

Even in the absence of oral habits, malocclusion was observed, this clearly points out that there could be etiological factors other than pernicious oral habits that could be the reason for malocclusions ${ }^{[5,9,15]}$ which would need further investigation. And from various above mentioned studies its showing that malocclusions are increasing in percentage from primary to permanent dentition hence all the hindrances in the path of natural growth once eliminated will help natural growth by itself to become the solution to the problem.

However, the limitations of this study were the intensity, frequency and duration of the oral habit which do have a role to play in developing malocclusion; however, in this study, there is no information to describe the relationship between duration of these habits and malocclusion owing to cross-sectional study design.

\section{CONCLUSION}

We found a prevalence of $8.9 \%$ of children with different types of malocclusion in the total sample size of 800 , and the prevalence of oral habits observed was $47.2 \%$. It is very important to advice children to refrain from tongue thrust, mouth-breathing and thumb sucking. The correlation between prevalence of oral habits and malocclusions in deciduous dentition does not seem to be strong, but we found tongue thrusting and mouthbreathing habit more in this age group constituting $29.5 \%$ and $26.2 \%$, respectively contributing to the malocclusions. Hence, early attention must be given to these malocclusions mainly posterior crossbites and sagittal malrelationships and motivate the parents to eliminate these habits before damage is done to the permanent dentition as ideal primary dentition is the indicator of future ideal permanent dentition. 


\section{REFERENCES}

1. Yamaguchi H, Sueishi K. Malocclusion associated with abnormal posture. Bull Tokyo Dent Coll 2003;44:43-54.

2. Chevitarese AB, Della Valle D, Moreira TC. Prevalence of malocclusion in 4-6 year old Brazilian children. J Clin Pediatr Dent 2002;27:81-5.

3. Mistry P, Moles DR, O'Neill J, Noar J. The occlusal effects of digit sucking habits amongst school children in Northamptonshire (UK). J Orthod 2010;37:87-92.

4. Cozza P, Baccetti T, Franchi L, Mucedero M, Polimeni A. Transverse features of subjects with sucking habits and facial hyperdivergency in the mixed dentition. Am J Orthod Dentofacial Orthop 2007;132:226-9.

5. Warren JJ, Slayton RL, Bishara SE, Levy SM, Yonezu T, Kanellis MJ. Effects of nonnutritive sucking habits on occlusal characteristics in the mixed dentition. Pediatr Dent 2005;27:445-50.

6. Cozza P, Baccetti T, Franchi L, Mucedero M, Polimeni A. Sucking habits and facial hyperdivergency as risk factors for anterior open bite in the mixed dentition. Am J Orthod Dentofacial Orthop 2005;128:517-9.

7. Tausche E, Luck O, Harzer W. Prevalence of malocclusions in the early mixed dentition and orthodontic treatment need. Eur J Orthod 2004;26:237-44.

8. Goel P, Sequeira P, Peter S. Prevalence of dental disease amongst 5-6 and 12-13 year old school children of Puttur municipality, Karnataka StateIndia. J Indian Soc Pedod Prev Dent 2000;18:11-7.

9. Duncan K, McNamara C, Ireland AJ, Sandy JR. Sucking habits in childhood and the effects on the primary dentition: Findings of the Avon Longitudinal Study of Pregnancy and Childhood. Int J Paediatr Dent 2008;18:178-88.

10. Abu Alhaija ES, Qudeimat MA. Occlusion and tooth/arch dimensions in the primary dentition of preschool Jordanian children. Int J Paediatr Dent 2003;13:230-9.

11. Khinda V, Grewal N. Relationship of tongue-thrust swallowing and anterior open bite with articulation disorders: A clinical study. J Indian Soc Pedod Prev Dent 1999;17:33-9.

12. Motta LJ, Bachiega JC, Guedes CC, Laranja LT, Bussadori SK. Association between halitosis and mouth breathing in children. Clinics (Sao Paulo) 2011;66:939-42.

13. Frazão P, Narvai PC, Latorre Mdo R, Castellanos RA. Are severe occlusal problems more frequent in permanent than deciduous dentition? Rev Saude Publica 2004;38:247-54.

14. Fukuta O, Braham RL, Yokoi K, Kurosu K. Damage to the primary dentition resulting from thumb and finger (digit) sucking. ASDC J Dent Child 1996;63:403-7.

15. Vázquez-Nava F, Quezada-Castillo JA, Oviedo-Treviño S, SaldivarGonzález AH, Sánchez-Nuncio HR, Beltrán-Guzmán FJ, et al. Association between allergic rhinitis, bottle feeding, non-nutritive sucking habits, and malocclusion in the primary dentition. Arch Dis Child 2006;91:836-40.

16. Nanda RS, Khan I, Anand R. Effect of oral habits on the occlusion in preschool children. ASDC J Dent Child 1972;39:449-52.

17. Mattar SE, Anselmo-Lima WT, Valera FC, Matsumoto MA. Skeletal and occlusal characteristics in mouth-breathing pre-school children. J Clin Pediatr Dent 2004;28:315-8

18. Cheng MC, Enlow DH, Papsidero M, Broadbent BH Jr, Oyen O, Sabat M. Developmental effects of impaired breathing in the face of the growing child. Angle Orthod 1988;58:309-20.

19. Bresolin D, Shapiro GG, Shapiro PA, Dassel SW, Furukawa CT, Pierson WE, et al. Facial characteristics of children who breathe through the mouth. Pediatrics 1984;73:622-5.

20. Stevart RE, Arber TK, Troutman KC, Wei SH. Pediatric Dentistry Scientific Foundations and Clinical Practice. St. Louis, Missouri: C V Mosby and Company; 1982

21. Gellin ME. Digital sucking and tongue thrusting in children. Dent Clin North Am 1978;22:603-19.

How to cite this article: Chour RG, Pai SM, Chour GV, Kenchappannavar SM, Parameshwarappa P. Assessment of various deleterious oral habits and its effects on primary dentition among 3-5 years old children in Davangere city. J Pediatr Dent 2014;2:37-43.

Source of Support: Nil. Conflict of Interest: None declared. 